\title{
Effects of Different Variants of Plasma Nitriding on the Properties of the Nitrided Layer
}

\author{
Dorina Kovács (D), Iban Quintana, and János Dobránszky
}

\author{
(Submitted November 2, 2018; in revised form July 21, 2019; published online September 4, 2019)
}

\begin{abstract}
Several process variants of plasma nitriding can be distinguished depending on the location of the voltage introduction. The aim of this study is to compare three different variants of plasma nitriding (DC plasma nitriding, active screen plasma nitriding, and active screening process with bias voltage application) extended by the study of the coverage of active screen on $\mathrm{C} 45 \mathrm{E}$ unalloyed steel, using two different $\mathrm{N}_{2}-\mathrm{H}_{2}$ gas mixtures. The thickness of the compound layer was measured using a scanning electron microscope, the phase analysis was performed by an $x$-ray diffractometer, and the nitrogen contents were analyzed by glow discharge optical electron spectroscopy. The results showed that the layer thickness and the surface hardness were higher by using active screen-biased plasma nitriding with high $\mathbf{N}_{2}$ content gas mixture. Besides, the lid of the active screen did not influence significantly the chemical composition of the compound layer.
\end{abstract}

Keywords active screen plasma nitriding, GDOES, surface characterization

\section{Introduction}

Plasma nitriding is a thermochemical surface treatment process to create a hard, wear-resistant layer on steel surfaces (Ref 1-4). The conventional, direct current plasma nitriding (DCPN) (Ref 5, 6) is now more than 60 years old (Ref 7). Today, it is widely used in many areas of the industry for example in automotive industries, machine tool manufacturing, etc. The process is popular because it requires less gas compared to gas nitriding and is more environmentally friendly compared to salt bath nitriding. In the DCPN treatment, plasma is generated directly on the workpiece leading to various problems: (1) edge effect (Ref 8,9) and (2) hollow cathode effect (Ref 10, 11). Typical technological problem is the edge effect that can be observed along the edges and corners of the samples, where nitrogen can diffuse into these parts from multiple directions which result in a nitride network along the particle boundaries. The edge effect can be easily observed as the workpiece color is not uniform, and this effect can result in the embrittlement of the effected edges and corners, causing the easier break of the corners for example. The consequence of the edge effect is clearly visible on the microscopic images of cross-sectional samples which are also confirmed by hardness tests in the research of Sousa et al. (Ref 12) and Alves et al. (Ref 13). In addition to the edge effect, hollow cathode effect

Dorina Kovács, Department of Materials Science and Engineering, Faculty of Mechanical Engineering, Budapest University of Technology and Economics, Müegyetem rakpart 3., Budapest 1111, Hungary; Iban Quintana, IK4-Tekniker, Eibar, Spain; and János Dobránszky, MTA-BME Research Group for Composite Science and Technology, Budapest, Hungary. Contact e-mail: dorina@eik.bme.hu. can also occur in adjacent parts and holes with small diameters which lead to local overheating (Ref 14, 15) and may cause changes in the microstructure and consequently in the mechanical properties.

To solve the shortcomings mentioned above, a different kind of process solution was developed, called active screen plasma nitriding (ASPN) (Ref 16-18). In this case, the plasma is not created on the workpiece, but on a screen (often called as a cage) placed around the workpiece. In this process, the workpiece is completely insulated from the source of the voltage, the screen fulfills the role of the cathode, and the furnace wall is still the anode. Since the workpiece is not acting as the cathode anymore, the edge effect and the hollow cathode effect are eliminated; however, in the case of ASPN, the heating time maybe longer. In order to reduce the heating time back to the DCPN process time, a lower voltage (bias voltage) than the active screen's is applied to the sample (Ref 9, 19); this process is the so-called active screen-biased plasma nitriding process (ASBPN). The application of bias is an extended option of the ASPN process especially in the industry, in order to obtain homogeneous heating of a large number of parts. The workpiece is heated for the same time with heat radiation and direct heating, but the voltage is not high enough to cause DCPN problems to develop significantly. Based on the previous studies, the applied bias voltage in laboratories is typically around 4\% (Ref 20); in the industrial applications, it is often set to $15 \%$ (Ref 21 ) of the high voltage circuitry. These settings result in trouble-free nitriding, but the further increase in voltage causes problems like the ones that occur during the DCPN process (Ref 21, 22).

In this study, the above-mentioned three different variants of plasma nitriding (DCPN, ASPN, and ASBPN) were compared extended by the study of the effect of the lid of the active screen. Furthermore, the gas mixture of low and high nitrogen content was also investigated. Li et al. (Ref 23) nitrided with lower $\mathrm{H}_{2}$ content gas mixture $\left(25 \% \mathrm{H}_{2}-75 \% \mathrm{~N}_{2}\right)$ without the top lid of the active screen which produced a non-uniform, grayscale surface. Toward the edges, the sample surface was darker, and the hardness was lower than in the center of the surface. In the center, the depth profile of the hardness was the 
same as when using a top lid. Ahanganari et al. (Ref 24) also investigated the coverage of active screen, but with higher nitrogen content, $25 \% \mathrm{H}_{2}-75 \% \mathrm{~N}_{2}$ was used with different hole size active screens. According to their experience, the layer thickness was similar regardless of the hole sizes of the screen. Plate lid has been also tried which caused a small increase in the nitrided layer thickness. Based on the mentioned studies, the effect of the lid has not been proved yet.

\section{Materials and Methods}

The material used in this study was $\varnothing 20 \times 6 \mathrm{~mm}$ annealed, grade $\mathrm{C} 45 \mathrm{E}$ unalloyed steel with the following chemical composition in wt.\% C 0.44, Si 0.28, Mn 0.8 Fe bal. Unalloyed steel was chosen because in this case, the alloying does not influence the formation of the nitride layer. The samples were machined from a $\varnothing 20-\mathrm{mm}$ annealed rod. The average hardness value of the base material was measured as $250 \mathrm{HV} 0.05$. The samples were ground on P80 to P2500 SiC particle size papers, and then polished by a $3 \mu \mathrm{m}$ diamond suspension. Finishing of the preparation was done by degreasing in acetone.

Various arrangements of the plasma nitriding equipment are shown in Fig. 1. The material of the cage was 1.0330 coldrolled unalloyed steel with a hole size of $\varnothing 5 \mathrm{~mm}$, a center distance of $8 \mathrm{~mm}$, and overall dimensions of $\varnothing 100 \times 85 \times 1 \mathrm{~mm}$. In the DCPN process, the cathode was the sample, and the heat shield placed around was the anode. In the ASPN process, the cage serves as the cathode, the sample was completely insulated from the source of the voltage, but was not grounded, and hence it was on floating potential. When using bias voltage, the sample was connected to the heat shield as a cathode; in the present study, the bias voltage value is $20 \%$ of the main circuit voltage. The samples were at the center of the active screen, the distance from the lid was $35 \mathrm{~mm}$. The temperature was monitored using an isolated K-type thermocouple under the workpiece.

Plasma nitriding experiments began with the vacuum space depressurization to 0.16 mbar. The next step was the displacement of residual air, which was done by argon rinsing. After the rinsing was complete, the pump depressurizes the space again, and then the nitriding process began after the hydrogennitrogen gas mixture was injected. During an approximately $30 \mathrm{~min}$ heating period, the plasma has reached the treatment temperature of $490^{\circ} \mathrm{C}$, from which the $4 \mathrm{~h}$ treatment time must be counted. All treatments were carried out using the same parameters as shown in Table 1 .

After $4 \mathrm{~h}$, the sample was cooled under the operating pressure of $2.8 \mathrm{mbar}$ for $20 \mathrm{~min}$. During this time, the sample was cooling down to $\sim 300{ }^{\circ} \mathrm{C}$. Further cooling to room temperature happened after the vacuum pump was disengaged. After the air was let into the chamber, the sample cooled down, and accordingly the free cooling of the sample took place.

Stereomicroscopic (Olympus SZX16) images were taken from the upper surfaces of the nitrided samples. Subsequently, layer thickness measurements were performed by an optical microscope (Olympus PMG-3) and by an SEM (Philips XL30). The mechanical properties (microhardness) of the layer were measured by a microhardness tester (Buehler IndentaMet 1105). The phases on the nitrided surface were analyzed in IK4-Tekniker Ltd., with a Bruker D8 ADVANCE x-ray diffractometer (theta-2 theta vertical goniometer, $\mathrm{Cr}$ target, scan parameters were $40^{\circ}-160^{\circ}$ in 2 thetas, the wavelength was $2.28 \mathrm{~nm}$, while the exposure time was set to $0.4 \mathrm{~s} / \mathrm{step}$ ). Nitrogen content measurements were made using glow discharge optical spectroscopy (GDOES) analysis with a Horiba GD-Profiler 2 type apparatus (flushing time of $5 \mathrm{~s}$, preintegration time of $100 \mathrm{~s}$, at the pressure of $650 \mathrm{~Pa}$, power of $35 \mathrm{~W}$, module voltage of $7.2 \mathrm{~V}$ and phase voltage of $4.7 \mathrm{~V}$ ). The wear tests were carried out on a Bruker UMT ball-on-disk tester, using a $\varnothing 3-\mathrm{mm} \mathrm{Al}_{2} \mathrm{O}_{3}$ ball with $2 \mathrm{~N}$ load. The sliding distance was $100 \mathrm{~m}$, and the sliding speed was set to $0.1 \mathrm{~m} / \mathrm{s}$.

\section{Results and Discussion}

The pictures of the nitrided samples surfaces are shown in Fig. 2. Color gradients can be observed in the samples made with different procedures. The samples were nitrided by DCPN show discoloration caused by the edge effect, which to a lesser extent was appeared at the application of bias too. It can be also caused by the air inlet into the chamber. It could oxidize the

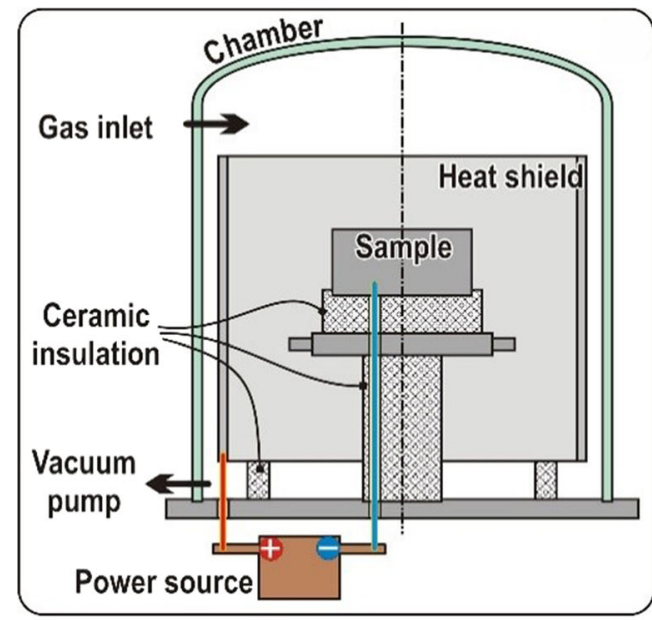

(a)

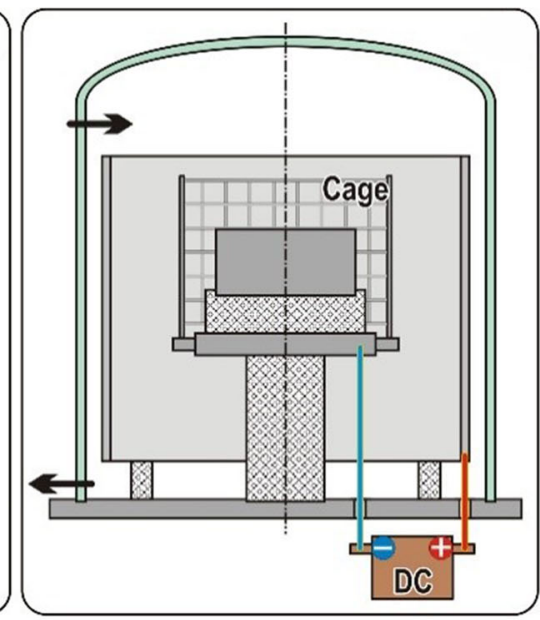

(b)

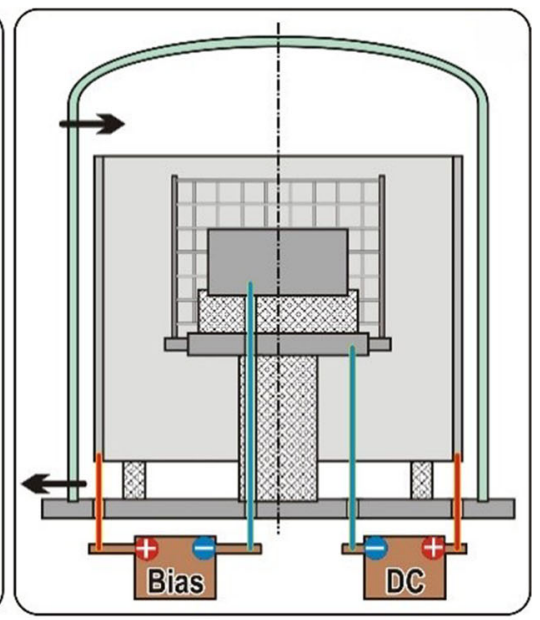

(c)

Fig. 1 Schematic diagrams of plasma nitriding arrangements (a) DCPN, (b) ASPN and (c) ASBPN 


\begin{tabular}{|c|c|c|c|c|}
\hline Temperature, $\mathbf{T},{ }^{\circ} \mathrm{C}$ & Pressure, p, mbar & Time, $\mathbf{t}, \mathbf{h}$ & Low $N_{2}$ content & High $N_{2}$ content \\
\hline 490 & 2.8 & 4 & $25 \% \mathrm{~N}_{2}-75 \% \mathrm{H}_{2}$ & $95 \% \mathrm{~N}_{2}-5 \% \mathrm{H}_{2}$ \\
\hline
\end{tabular}

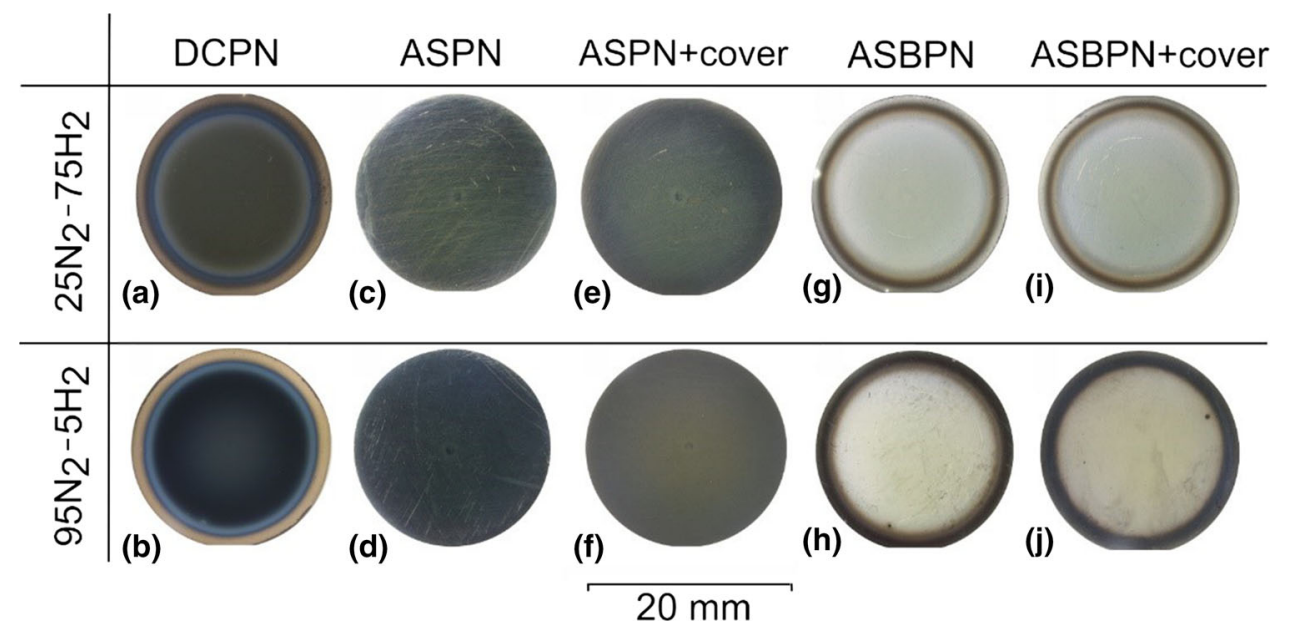

Fig. 2 Images of the plasma nitrided surfaces by different electric arrangements with various gas mixtures. All group of pictures have a similar arrangement: (a)-(b) DCPN-, (c)-(d) ASPN-, (e)-(f) ASPN + lid-, (g)-(h) ASBPN-, (i)-(j) ASBPN + lid-treated samples

overheated surface. Because of the capability of the equipment, the bias voltage was higher than the suggested by the previous research (Ref 20), so the discoloration appeared on the edges. The edge effect appeared independently from the composition of the gas mixture, so it was proven that the edge effect was dependent only on the procedure rather than the gas composition. It can also be seen that if the sample was connected as a cathode, even to a low voltage, i.e., the current of the electric circuit flows through it, the forced diffusion of nitrogen is realized from the nitrogen plasma, and this will be the cause of the edge effect.

Furthermore, the lid of the active screen slightly influenced the surface. The residual scratches of the sample preparation were disappeared with using the lid. This phenomenon was observed only in the case of ASPN samples.

The microstructure of the nitrided samples and the formed compound layer are shown in Fig. 3, while the measured layer thicknesses is given in Table 2. The concept of evenness was introduced which is the average of the layer thickness including the waves. The compound layer appeared in each sample. The thickest layer was formed on the ASBPN sample made with gas mixture composition of $95 \mathrm{~N}_{2}-5 \mathrm{H}_{2}$, which resulted in a thickness of $12 \mu \mathrm{m}$. In both cases, the ASPN samples had the smallest compound layer thickness at any gas mixture, which was about $4 \mu \mathrm{m}$. Besides the presence of bias voltage, the layer thickness of the ASBPN process was higher than in the case of DCPN process, at least with high nitrogen content. Contrarily in the low nitrogen content gas mixture, the layer thickness was similar in both processes.

The results of the microhardness measurements were grouped for both gas mixtures and are shown in Fig. 4. The first value on the hardness profile was measured on the top of the surface, and the other points were measured on the cross section. The highest hardness was achieved in the case of DCPN process in both gas mixtures. With each gas mixture, the ASPN samples had the lowest hardness values, which were between 510 and 560 HV0.05. For DCPN and ASBPN, the hardness increased more than twice, but with the use of the active screen, it has been just slightly doubled. This is due to the fact that in the ASPN process, the incorporation of nitrogen into the surface on floating potential did not happen by forced diffusion (rather by spontaneous nitrogen diffusion) (Ref 25, 26), and therefore the distribution and morphology of the nitride phases formed from the ferrite and the remaining ferrite will be different; this question should be further explored in a subsequent publication. The maximum hardness and also the hardness profile were similar with or without the lid of the active screen.

The hardness curves are suitable for determining the thickness of the diffusion zone. Based on the ISO 18203:2016 standard, the size of the diffusion zone is the distance value between the surface and the base hardness +50 HV. The latter was indicated by a horizontal dashed line in the diagrams at $300 \mathrm{HV} 0.05$ (Fig. 4). Because the hardness profiles were similar with or without the top lid, the diffusion zones thicknesses were also almost the same. It is observed that the diffusion zones of $25 \mathrm{~N}_{2}-75 \mathrm{H}_{2}$ gas mixture samples were almost equal to each other $(\sim 40 \mu \mathrm{m})$, but the three electric arrangement sample diffusion zones on $95 \mathrm{~N}_{2}-5 \mathrm{H}_{2}$ gas mixture were significantly different. The highest value-without the thickness of the compound layer-is $55 \mu \mathrm{m}$, the lowest was $20 \mu \mathrm{m}$. The most conspicuous difference was at ASBPN-treated samples. The diffusion zone was lower than the ASPN at both gas mixtures. The maximum hardness values were also lower than in the case of $25 \% \mathrm{~N}_{2}-75 \% \mathrm{H}_{2}$ gas mixture samples. Probably, the energy of the high content nitrogen gas mixture 

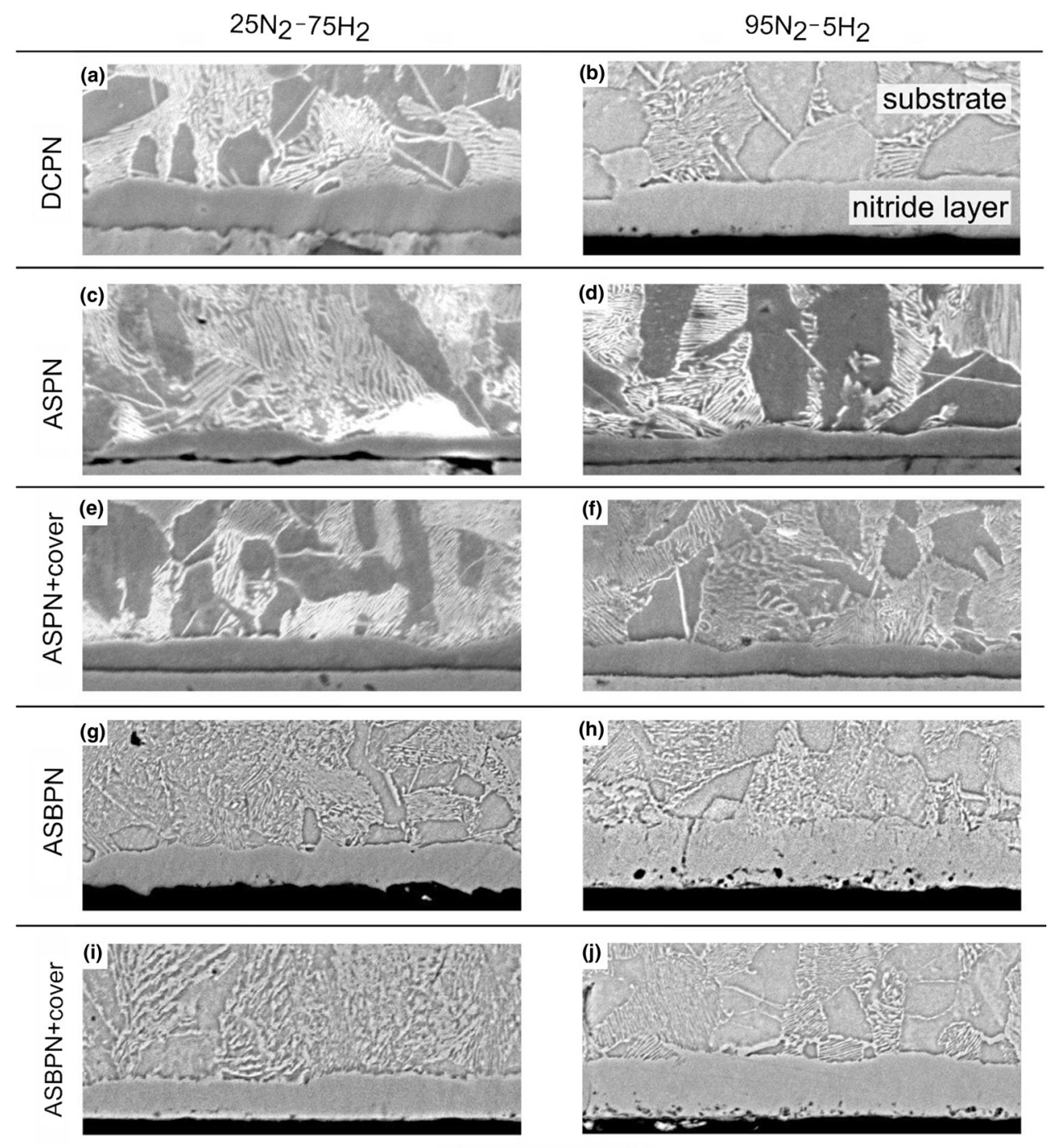

$\longmapsto 20 \mu \mathrm{m}$

Fig. 3 SEM images of plasma nitrided samples by different electric arrangements with various gas mixtures. All group of pictures has a similar arrangement: (a)-(b) DCPN-, (c)-(d) ASPN-, (e)-(f) ASPN + lid-, (g)-(h) ASBPN-, (i)-(j) ASBPN + lid-treated samples

Table 2 Measured and calculated compound layer thicknesses of nitrided samples

\begin{tabular}{lcclll}
\hline & \multicolumn{2}{c}{ Measured } & & \multicolumn{2}{c}{ Calculated } \\
\cline { 2 - 3 } \cline { 6 - 7 } & $\mathbf{2 5 N}_{\mathbf{2}} \mathbf{- 7 5} \mathbf{H}_{\mathbf{2}}$ & $\mathbf{9 5 N}_{\mathbf{2}} \mathbf{- 5} \mathbf{H}_{\mathbf{2}}$ & & $\mathbf{2 5 N}_{\mathbf{2}} \mathbf{- 7 5 \mathbf { H } _ { 2 }}$ & $\mathbf{9 5 N}_{\mathbf{2}} \mathbf{- 5} \mathbf{H}_{\mathbf{2}}$ \\
\hline DCPN & $7 \mu \mathrm{m}$ & $10 \mu \mathrm{m}$ & & $7 \mu \mathrm{m}$ & $10 \mu \mathrm{m}$ \\
ASPN & $4 \mu \mathrm{m}$ & $4 \mu \mathrm{m}$ & & $\ldots$ & $\ldots$ \\
ASPN + lid & $4 \mu \mathrm{m}$ & $4 \mu \mathrm{m}$ & & $5 \mu \mathrm{m}$ & $5 \mu \mathrm{m}$ \\
ASBPN & $7 \mu \mathrm{m}$ & $11 \mu \mathrm{m}$ & & $\ldots$ & $\ldots$ \\
ASBPN + lid & $7 \mu \mathrm{m}$ & $12 \mu \mathrm{m}$ & $7 \mu \mathrm{m}$ & $12 \mu \mathrm{m}$ \\
\hline
\end{tabular}

has lower energy for the sputtering. There was a slight nitrogen mass transfer to the surface which had a limited nitriding effect (Ref 23, 27-29).

It is shown in the x-ray diffractograms (Fig. 5) that each sample had the peak of $\mathrm{Fe}_{4} \mathrm{~N}$ next to the peak of Fe. The thickness of the compound layer can be deduced from the magnitude of the iron peak, which showed where the intensity was high, and the thickness of the compound layer was small. As it was confirmed by the SEM thickness measurements, the thickest layer was formed in the case of DCPN and ASBPN processes with lid (corresponding to the smallest Fe peaks in the diffractograms, see Fig. 5a), while the absolute thinnest layer was measured in the case of the ASPN process. These phenomena apply to the samples of $95 \mathrm{~N}_{2}-5 \mathrm{H}_{2}$ gas mixture too, namely the ASBPN process with lid had the thickest and also the ASPN-treated samples had the thinnest layers.

Comparing Fig. 5(a) and (c), it is observed that $\mathrm{Fe}_{3} \mathrm{~N}$ appeared in all of the nitrided samples with the $95 \mathrm{~N}_{2}-5 \mathrm{H}_{2}$ gas mixture, in contrast with the other gas mixture. The highest value of $\varepsilon$-phase was measured in the ASBPN samples at $95 \%$ $\mathrm{N}_{2}-5 \% \mathrm{H}_{2}$ gas mixture. This phenomenon confirmed the previous research (Ref 30) that stated $\mathrm{Fe}_{3} \mathrm{~N}$ was created with high nitrogen content gas mixture but was not a unique phase. It can be influenced by the short nitriding time or alloying. The quantitative analysis shows that in this case, the layer was thicker than $12 \mu \mathrm{m}$, and $100 \% \mathrm{Fe}_{4} \mathrm{~N}$ was measured. The $\mathrm{x}$-ray beam cannot penetrate the thickness of the compound layer. 

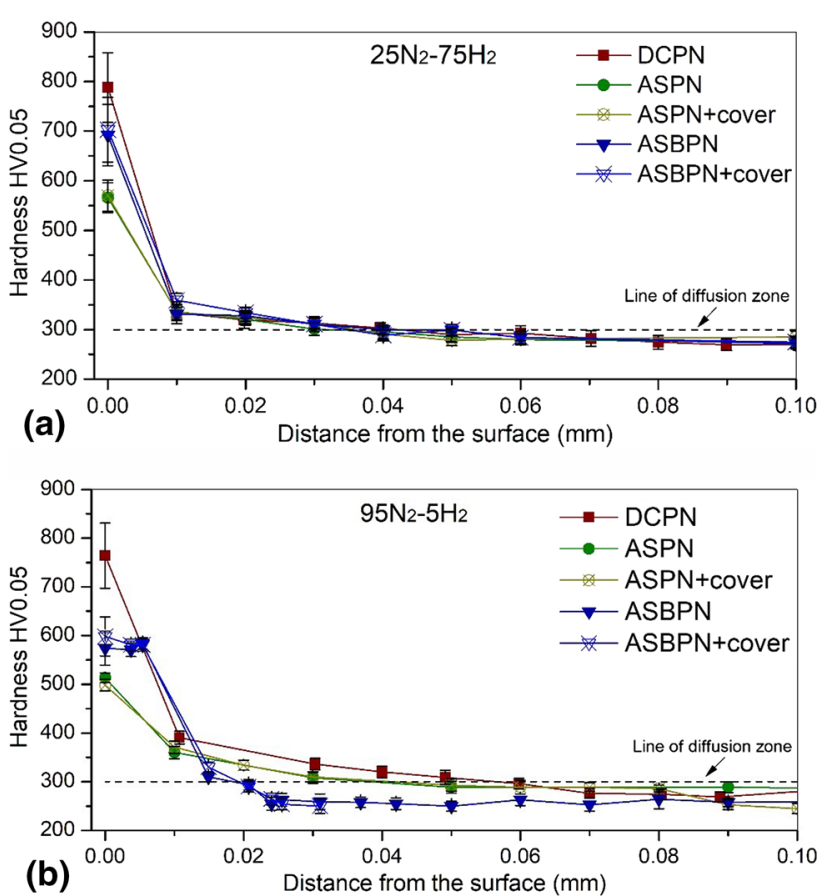

Fig. 4 Hardness profile of plasma nitrided samples with (a) $25 \%$ $\mathrm{N}_{2}-75 \% \mathrm{H}_{2}$ gas mixture, (b) $95 \% \mathrm{~N}_{2}-5 \% \mathrm{H}_{2}$ gas mixture
Previous analysis suggested that there is no significant difference between active screen plasma nitriding with or without the top lid; to confirm this result, the three electric arrangements were further analyzed by GDOES.

The quantitative measurement of the nitrogen content from the GDOES measurement depending on the depth measured from the surface is shown in Fig. 6.

The depth profile of nitrogen content can be experimentally described with a sigmoid tanh curve. The original measured data show the measurement points (pink line in Fig. 6(a)). During the fitting of the curve, the beginning of the data was cut. The fit curve was started from that point where the halfwidth maximum of oxygen content was found (Fig. 7).

According to the Fick I and II laws (Ref 31, 32), which are formulated by linear partial differential equations, the solutions can be expressed by some combination of exponential and trigonometric functions. Equation 1 can be properly fitted on the nitrogen content measurement data.

$N(x)=a \mathrm{e}^{-b x}+\frac{c}{2}\left(1+\tanh \left(-\frac{x+d}{\varepsilon}\right)\right)+g$

where $N(x)$ is the nitrogen content, $x$ is the distance from the maximum point $(a+c+g)$ of the nitrogen profile. The initial decay is denoted by $b$, while the height and the center of the sigmoid are given by $c$ and $d$. The "smoothness" parameter of

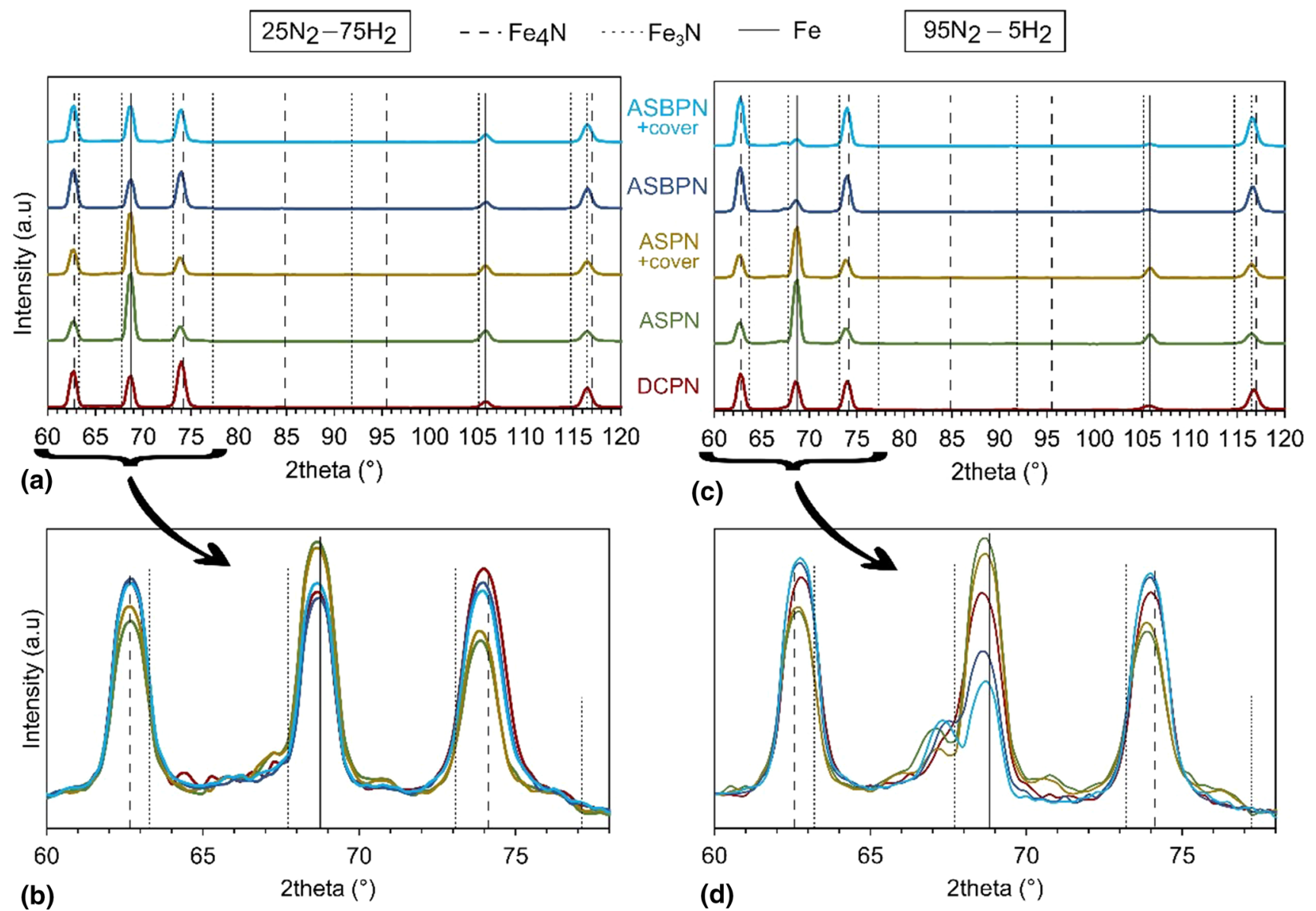

Fig. 5 Diffraction patterns of plasma nitrided samples. The a and c figures have a logarithmical intensity scale which can show the differences between $\varepsilon-(\mathrm{Fe} 3 \mathrm{~N})$ and $\gamma^{\prime}-(\mathrm{Fe} 4 \mathrm{~N})$ phases. (a)-(b) $25 \% \mathrm{~N}_{2}-75 \% \mathrm{H}_{2}$, (c)-(d) $95 \% \mathrm{~N}_{2}-5 \% \mathrm{H}_{2}$ 

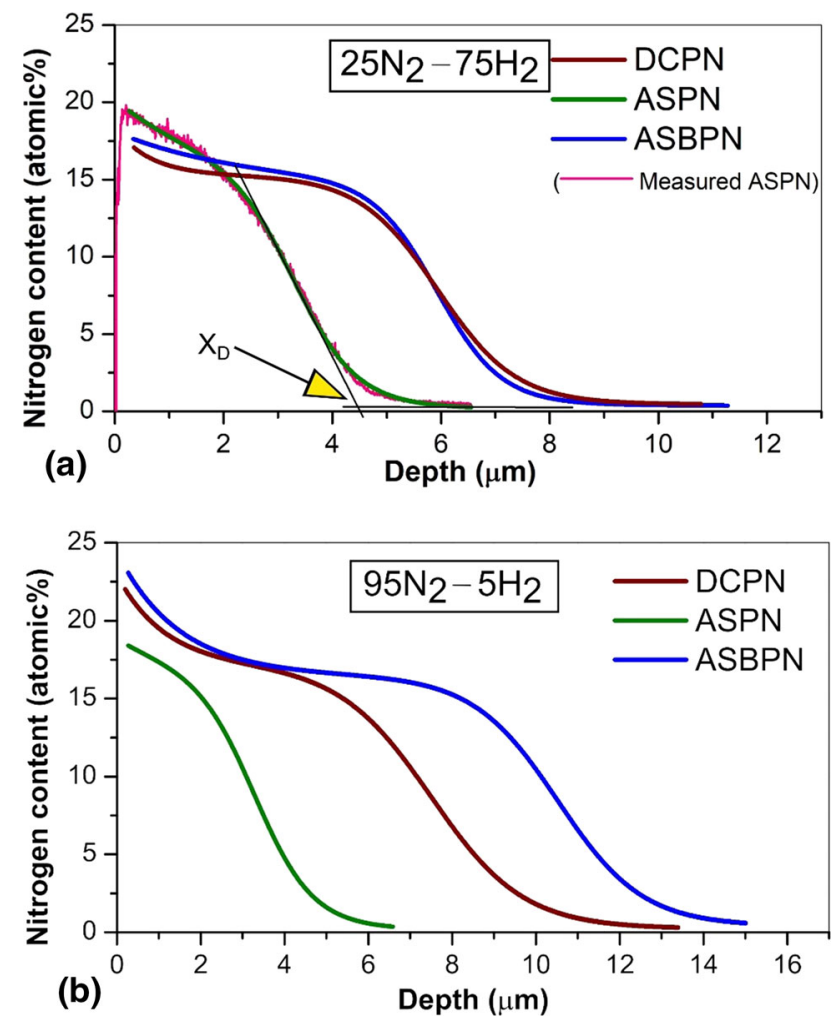

Fig. 6 Nitrogen content profiles of nitrided samples (a) $25 \% \mathrm{~N}_{2-}$ $75 \% \mathrm{H}_{2}$ gas mixture, (b) $95 \% \mathrm{~N}_{2}-5 \% \mathrm{H}_{2}$ gas mixture

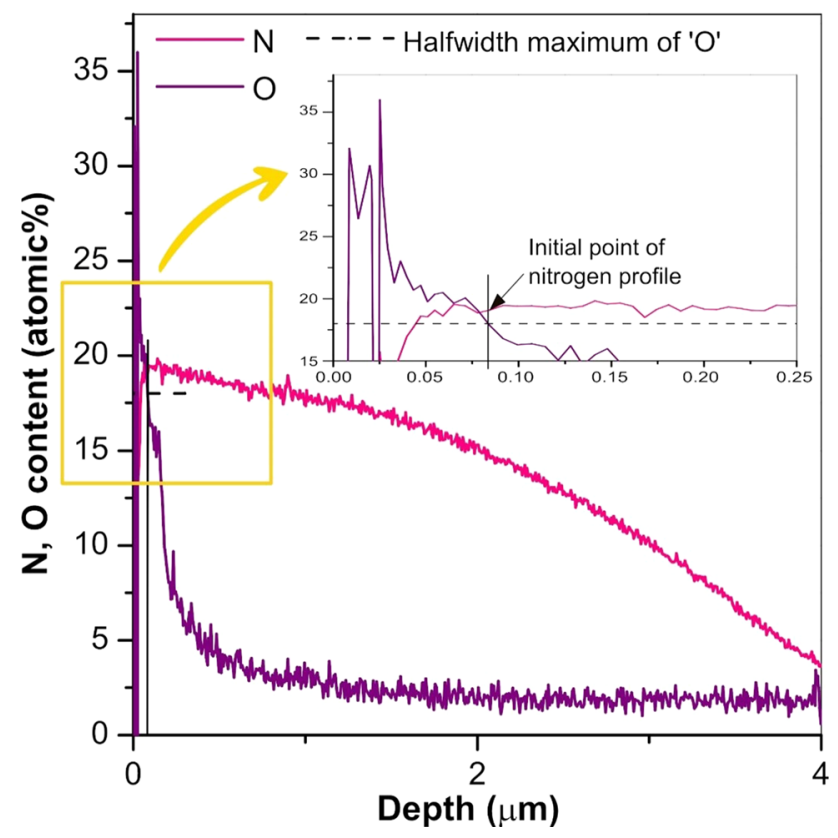

Fig. 7 Determination of the initial point at ASPN nitrogen profile

the sigmoid is $\varepsilon$, and $g$ is the concentration far from the initial point, which in fact expected to be zero.

Consequently, the layer thickness can be determined. It is at the highest concave curvature point, which is approximated by the intersection of the line of 0 at.\% nitrogen content and the extended line of the gradient of tanh function at its inflexion point. This intersection point $\left(x_{\mathrm{D}}\right.$, yellow arrow in Fig. 6(a)) is calculated according to Eq 2. The calculated data are shown in Table 2 .

$x_{\mathrm{D}}=d+\varepsilon-2 a \varepsilon \frac{b \varepsilon-1}{2 a b \varepsilon+a \mathrm{e}^{b d}}$

According to the experiment of Hosseini et al. (Ref 33), the compound layer was a nearly horizontal section of the nitrogen profile, but it was typically found in stainless steel. In this case, we can only talk about a nitrided layer, and there was no subsequent independent diffusion zone found in unalloyed steels. Nitrogen flow also returned to 0 at.\% that the phase so far represented the compound layer.

The maximum nitrogen content was measured on the samples of the $95 \mathrm{~N}_{2}-5 \mathrm{H}_{2}$ gas mixture, which had a lower hardness than the samples produced in the $25 \mathrm{~N}_{2}-75 \mathrm{H}_{2}$ gas mixture. The $\varepsilon$-phase $\left(\mathrm{Fe}_{3} \mathrm{~N}\right)$ was a porous layer (Fig. $3 \mathrm{~h}$ and $\mathrm{j}$ ), and the nitrogen content was lower than $\gamma^{\prime}$-phase $\left(\mathrm{Fe}_{4} \mathrm{~N}\right)$, so the maximum hardness was lower because of the loose structure.

The compound layer of the SEM measurements was lower by a few microns as the GDOES results, whereas the results of the methods were similar; therefore, the two measurements can be substituted by each other from the point of view of compound layer determination.

The wear tracks were plotted in $2 \mathrm{D}$ profiles as shown in Fig. 8 with the deepest part of the abraded sample. The profile was detected by confocal laser scanning microscope. The zero point was defined as the top of the surface far away from the abraded zone. The scanned cross-sectional profile was $1 \mathrm{~mm}$ away from the left end of the abraded zone. As it is seen, the depth profiles were really scattered which can be caused by the inaccuracy of the microscope. Despite this scatter, the shape of the curves gave the expected pattern. In Fig. 8(a) and (b), the color scale minimum and maximum values were related to the deepest and the highest point of the associated samples, respectively.

The wear track SEM images of plasma nitrided samples with different gas mixtures are shown in Fig. 9. Parallel abrasion grooves were observed in wear tracks in all of the treated surface. Compared to the original nitrided surface, the worn area of the sample had finer roughness. The tracks were relatively narrow and smooth except the ASPN samples. Figure 9(d) and (f) has just minor tracks, which refers excellent wear behavior among considered specimens. EDS analysis in the cracked area of the ASPN samples (Fig. 9b and e) shows a high content of oxygen indicating that the area was partially oxidized during the test, which is not unique (Ref 36-39). In this case, wear debris were stuck in the center of the track. It was caused by the initial wear of the diffusion zone. Besides this high $\mathrm{O}$ content, the other nitrided samples show some oxide scales, suggesting that the wear mechanism under the present test condition is oxidation.

The wear test results of the nitrided samples are shown in Fig. 10. Both ASPN process had the highest value because the diffusion zone was started to wear under the compound layer which is shown in Fig. 8. The wear track was deeper than the thickness of the iron-nitride layer. The wear rates of the nitrided samples by DCPN process were the same. While the DCPN samples wore similarly, until then between the results of the ASBPN samples had a bigger step. It was caused by the formation of the $\varepsilon$-phase. Porosity could be created in this phase, which was seen in this sample. If the porosity was formed, the wear rate could increase. As it was observed, the 

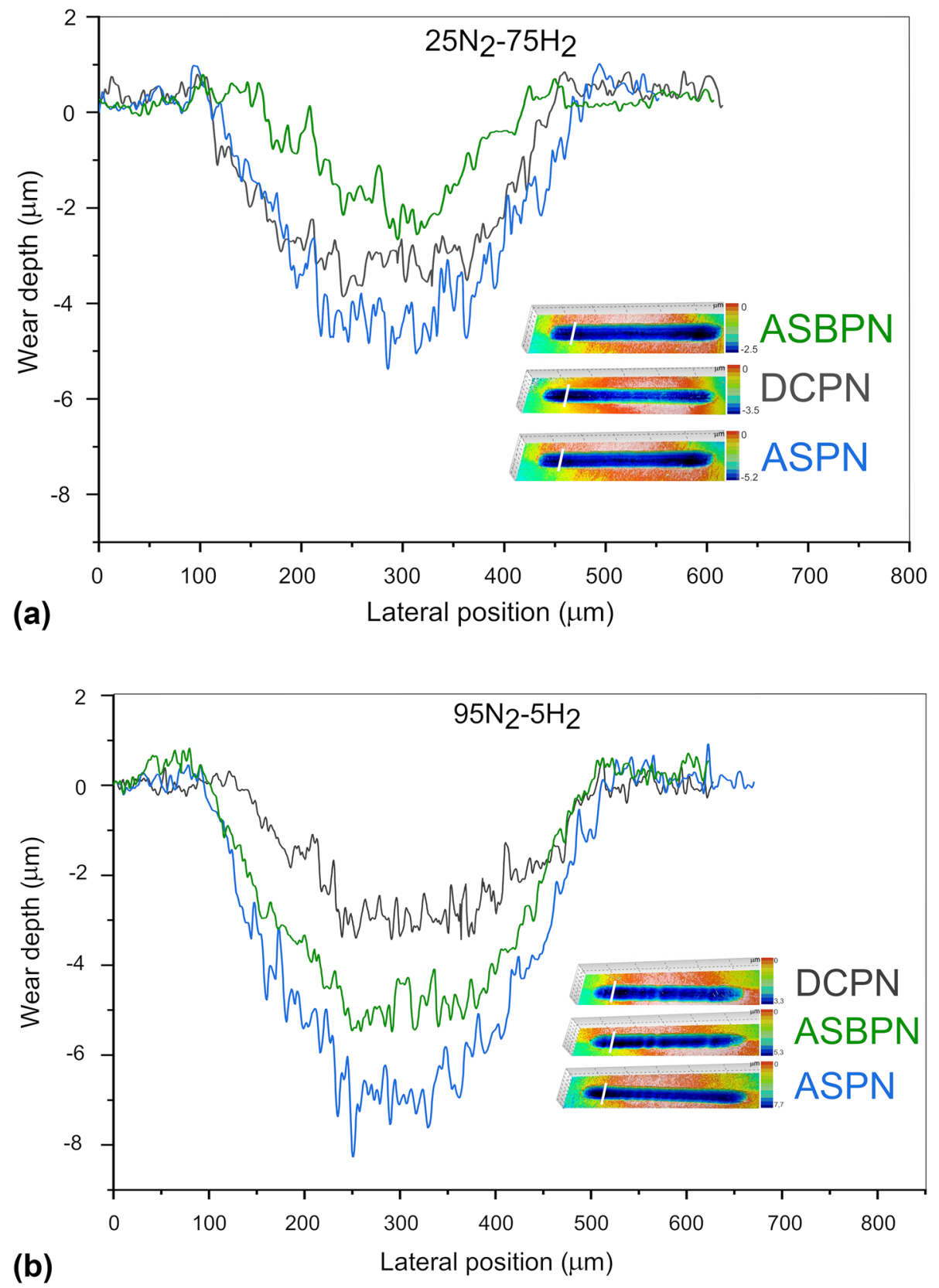

Fig. 8 Scanned profile of the nitrided samples with (a) $25 \% \mathrm{~N}_{2}-75 \% \mathrm{H}_{2}$ gas mixture, (b) $95 \% \mathrm{~N}_{2}-5 \% \mathrm{H}_{2}$ gas mixture

ASBPN process with $25 \mathrm{~N}_{2}-75 \mathrm{H}_{2}$ gas mixture resulted in the lowest wear rate. Naeem et al. and Conci et al. observed that the wear rate was increasing with an increase in the nitrogen content on the gas mixture $(\operatorname{Ref} 34,35)$. This phenomenon was equal to these results because the wear rates were higher than the samples treated by lower nitrogen content gas mixture.

\section{Conclusions}

The aim of the research was to compare the variations in the layout of plasma nitriding on C45E unalloyed steel samples. From the results and discussions above, the following conclusions can be drawn. 


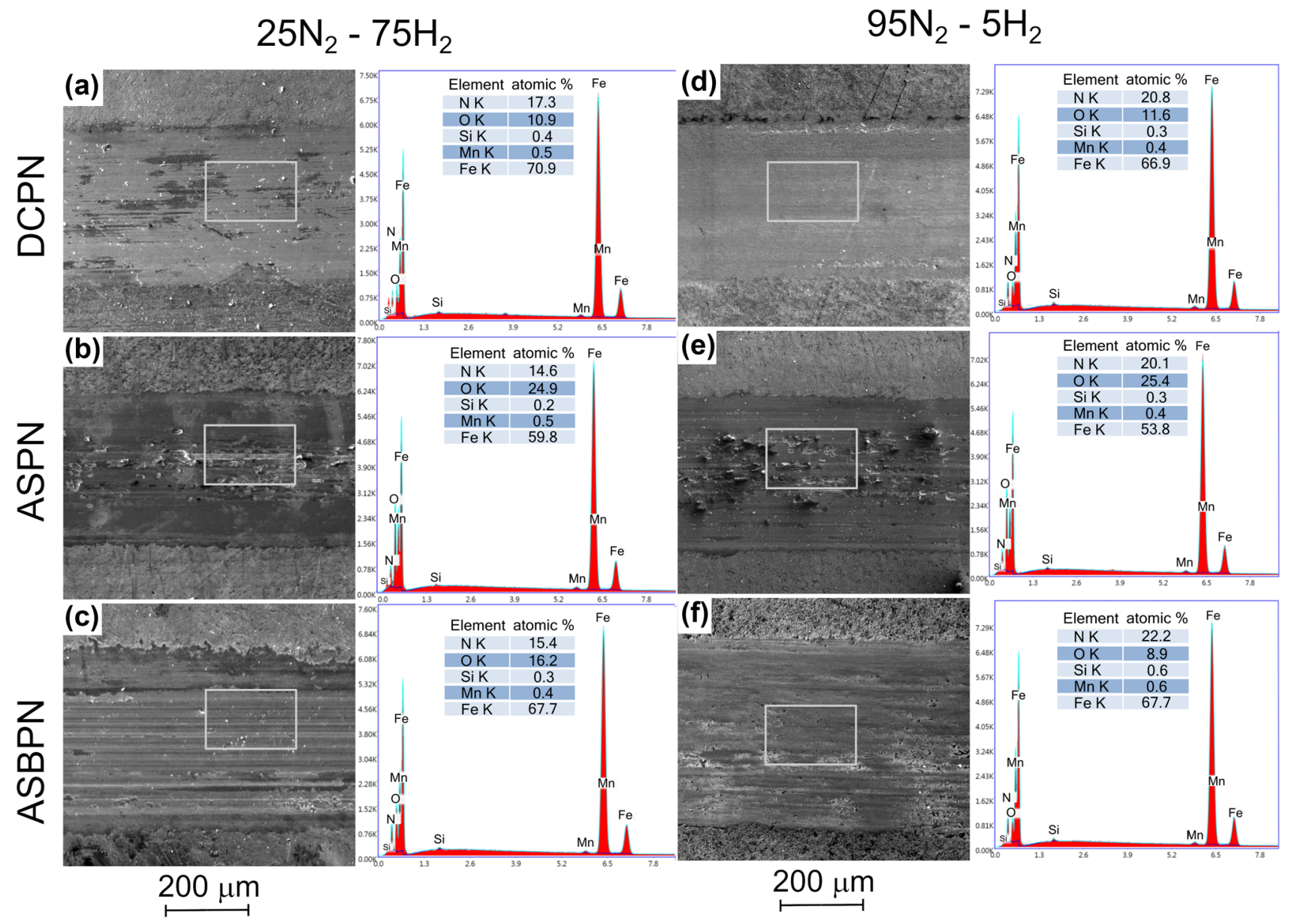

Fig. 9 SEM images of the worn surface of the (a)-(d) DCPN-, (b)-(e) ASPN-, (c)-(f) ASBPN-treated samples with different gas mixtures

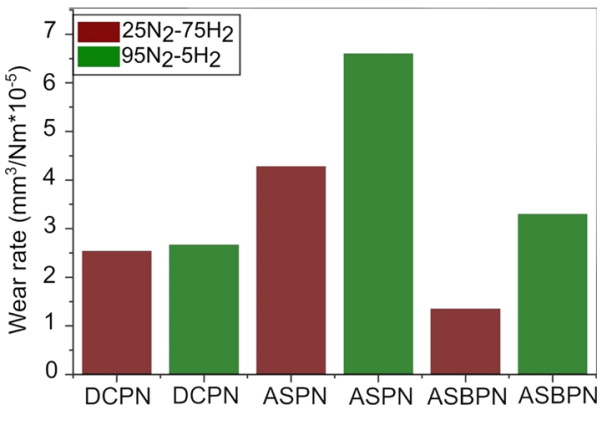

Fig. 10 Wear rate of the nitrided samples

- The application of active screen caused an evener layer thickness compared to other nitriding processes.

- In the DCPN samples, the hardness values were the highest, but with the use of bias, the hardness and the layer thickness can be increased compared to the active screen method.

- The lid of the active screen does not influence the properties of the nitrided layer.

- The applied equation can be properly fitted on the nitrogen content and able to describe the measurement data. The layer thickness is at the point of the highest concave curvature.

- From the different measurement methods and from the results of the mentioned mathematical process, the com- pound layer thickness values can be obtained with a few microns difference; therefore, all of the applied methods are reliable in the determination of the compound layer thickness.

- The wear rate was increasing with an increase in the nitrogen content on the gas mixture, due to additional porosity formed during the process.However, active screen plasma nitriding is an ideal process when there is no dynamical load between two parts. During DCPN, the compound layer is thick which may cause chipping along the edges. If only friction arises on the surfaces, this problem is not occurring; moreover, both the thicker layer and the higher hardness are advantageous.

\section{Acknowledgments}

Open access funding provided by Budapest University of Technology and Economics (BME). The authors are grateful to IK4-Tekniker, where the XRD and GDOES measurements were done. The authors are grateful to the foundation of Richter Gedeon Talentum for supporting this research. It was also supported by the BME-Nanonotechnology FIKP grant of EMMI (BME FIKP-NAT). The research reported in this paper has been supported by the National Research, Development and Innovation Fund (TUDFO/51757/2019-ITM, Thematic Excellence Program). 


\section{Open Access}

This article is distributed under the terms of the Creative Commons Attribution 4.0 International License (http://creativecommons.org/ licenses/by/4.0/), which permits unrestricted use, distribution, and reproduction in any medium, provided you give appropriate credit to the original author(s) and the source, provide a link to the Creative Commons license, and indicate if changes were made.

\section{References}

1. M. Naeem, M. Shafiq, M. Zaka-ul-Islam, N. Nawaz, J.C. Díaz-Guillén, and M. Zakaullah, Effect of Cathodic Cage Size on Plasma Nitriding of AISI, 304 Steel, Mater. Lett., 2016, 181, p 78-81

2. C.V. Robino and O.T. Inal, Ion Nitriding Behavior of Several Low Alloy Steels, Mater. Sci. Eng., 1983, 59(1), p 79-90

3. O.T. Inal and C.V. Robino, Structural Characterization of Some IonNitrided Steels, Thin Solid Films, 1982, 95, p 195-207

4. B. Katona, L. Nádai, E. Bognár, and P. Nagy, "Surface Treatments in Medical Technology, in International Engineering Symposium at Bánki, 2013, pp. 173-181

5. R. Grün and H.J. Günther, Plasma Nitriding in Industry-Problems, New Solutions and Limits, Mater. Sci. Eng. A, 1991, 140(C), p 435-441

6. K. Marchev, C.V. Cooper, J.T. Blucher, and B.C. Giessen, Conditions for the Formation of a Martensitic Single-Phase Compound Layer in Ion-Nitrided 316L Austenitic Stainless Steel, Surf. Coatings Technol., 1998, 99(3), p 225-228

7. D. Pye, Practical Nitriding and Ferritic Nitrocarburizing, ASM International, Russell Township, OH, 2003

8. M. Olzon-Dionysio, M. Campos, M. Kapp, S. de Souza, and S.D. de Souza, Influences of Plasma Nitriding Edge Effect on Properties of 316L Stainless Steel, Surf. Coatings Technol., 2010, 204(21-22), p 3623-3628

9. P. Hubbard, S.J. Dowey, J.G. Partridge, E.D. Doyle, and D.G. McCulloch, Investigation of Nitrogen Mass Transfer within an Industrial Plasma Nitriding System II: Application of a Biased Screen, Surf. Coatings Technol., 2010, 204(8), p 1151-1157

10. S. Janosi, Z. Kolozsvary, and A. Kis, Controlled Hollow Cathode Effect: New Possibilities for Heating Low-Pressure Furnaces, Met. Sci. Heat Treat., 2004, 46(7-8), p 310-316

11. L. Kenéz, N. Kutasi, E. Filep, L. Jakab-Farkas, and L. Ferencz, Anodic Plasma Nitriding in Hollow Cathode (HCAPN), HTM - J. Heat Treat. Mater., 2018, 73(2), p 96-105

12. R.R.M. de Sousa, F.O. de Araújo, K.J.B. Ribeiro, M.W.D. Mendes, J.A.P. da Costa, and C. Alves, Cathodic Cage Nitriding of Samples with Different Dimensions, Mater. Sci. Eng., A, 2007, 465(1-2), p 223 227

13. C. Alves, F.O. de Araújo, K.J.B. Ribeiro, J.A.P. da Costa, R.R.M. Sousa, and R.S. de Sousa, Use of Cathodic Cage in Plasma Nitriding, Surf. Coatings Technol., 2006, 201(6), p 2450-2454

14. Y. Li, L. Wang, L. Shen, D. Zhang, and C. Wang, Plasma Nitriding of $42 \mathrm{CrMo}$ Low Alloy Steels at Anodic or Cathodic Potentials, Surf. Coatings Technol., 2010, 204(15), p 2337-2342

15. J.J. Xu, L. Shen, and L. Wang, Plasma Nitriding of AISI, 304 Austenitic Stainless Steel Assisted with Hollow Cathode Effect, Surf. Coat. Technol., 2013, 228, p 456-459

16. S. Corujeira Gallo and H. Dong, On the Fundamental Mechanisms of Active Screen Plasma Nitriding, Vacuum., 2009, 84(2), p 321-325

17. S. Ahangarani, F. Mahboubi, and A.R. Sabour, Effects of Various Nitriding Parameters on Active Screen Plasma Nitriding Behavior of a Low-Alloy Steel, Vacuum, 2006, 80(9), p 1032-1037

18. Y. Li, Y. He, W. Wang, J. Mao, L. Zhang, Y. Zhu, and Q. Ye, Plasma Nitriding of AISI, 304 Stainless Steel in Cathodic and Floating Electric Potential: Influence on Morphology, Chemical Characteristics and Tribological Behavior, J. Mater. Eng. Perform., 2018, 27(3), p 948960

19. Y. Li, L. Wang, D. Zhang, and L. Shen, Influence of Bias Voltage on the Formation and Properties of Iron-Based Nitrides Produced by Plasma Nitriding, J. Alloys Compd., 2010, 497(1-2), p 285-289
20. K. Börner, I. Burlacov, H. Spies, H. Biermann, S. Hamann, and J. Röpcke, Investigations on the Active Screen Plasma Nitriding Process, in 13th International Conference on Plasma Surface Engineering, 2012, pp. 96-99

21. C.X. Li, Active Screen Plasma Nitriding-An Overview, Surf. Eng., 2010, 26(1-2), p 135-141

22. C. Zhao, C.X. Li, H. Dong, and T. Bell, Study on the Active Screen Plasma Nitriding and Its Nitriding Mechanism, Surf. Coatings Technol., 2006, 201(6), p 2320-2325

23. C.X. Li, T. Bell, and H. Dong, A Study of Active Screen Plasma Nitriding, Surf. Eng., 2002, 18(3), p 174-181

24. S. Ahangarani, A.R. Sabour, and F. Mahboubi, Surface Modification of 30CrNiMo8 Low-Alloy Steel by Active Screen Setup and Conventional Plasma Nitriding Methods, Appl. Surf. Sci., 2007, 254, p 14271435

25. S. Siddiqui, M. Dai, R. Loesing, E. Kaltalioglu, R. Pandey, R. Sathiyanarayanan, S. De, S. Raghavan, and H. Parks, Impact of Oxygen Plasma on Nitrided and Annealed Atomic Layer Deposited $\mathrm{SiO}_{2} /$ High-k/Metal Gate for High-Voltage Input and Output FinShaped Field Effect Transistor Devices, J. Vac. Sci. Technol. B Nanotechnol. Microelectron. Mater. Process. Meas. Phenom., 2017, 35(1), p 1-7

26. J.D. Ramshaw and C.H. Chang, Ambipolar Diffusion in TwoTemperature Multicomponent Plasmas, Plasma Chem. Plasma Process., 1993, 13(3), p 489-498

27. H. Jacobs, D. Rechenbach, and U. Zachwieja, Structure Determination of $\Gamma^{\prime}$-Fe4N and $\epsilon$-Fe3N, J. Alloys Compd., 1995, 227(1), p 10-17

28. Z.L. Zhang and T. Bell, Structure and Corrosion Resistance of Plasma Nitririded Stainless Steel, Surf. Eng., 1985, 1(2), p 131-136

29. E. Zdravecká, J. Slota, P. Solfronk, and M. Kolnerová, Evaluation of the Effect of Different Plasma-Nitriding Parameters on the Properties of Low-Alloy Steel, J. Mater. Eng. Perform., 2017, 26(7), p 3588-3596

30. S.B. Andrea, K.B. Mária, and M.B. Mária, Nitridálás - Korszerü Eljárások És Vizsgálati Módszerek Miskolc. (Miskolc, Miskolci Egyetem, 2012)

31. S.S. Hosmani, R.E. Schacherl, and E.J. Mittemeijer, The Kinetics of the Nitriding of $\mathrm{Fe}-7 \mathrm{Cr}$ Alloys; the Role of the Nitriding Potential, Mater. Sci. Technol., 2005, 21(1), p 113-125

32. A. Turk and C. Bindal, Characterization of Plasma Nitrided X32CrMoV33 Die Steel, Mater. Manuf. Process., 2009, 24(7-8), p 898-902

33. S.R. Hosseini and F. Ashrafizadeh, Accurate Measurement and Evaluation of the Nitrogen Depth Profile in Plasma Nitrided Iron, Vacuum, Elsevier Ltd, 2009, 83(9), p 1174-1178

34. M. Depianti, A. César, A. Ribeiro, and F. Jr., Effect of Plasma Nitriding Potential on Tribological Behaviour of AISI, D2 Cold-Worked Tool Steel, Wear, Elsevier, 2014, 317(1-2), p 188-193

35. M. Naeem, J. Iqbal, M. Abrar, K.H. Khan, J.C. Díaz-Guillén, C.M. Lopez-Badillo, M. Shafiq, M. Zaka-ul-Islam, and M. Zakaullah, The Effect of Argon Admixing on Nitriding of Plain Carbon Steel in N2 and N2-H2 Plasma, Surf. Coatings Technol., 2018, 350, p 48-56

36. I. Braceras, I. Ibáñez, S. Dominguez-Meister, J.A. Sánchez-García, M. Brizuela, A. Larrañaga, and I. Garmendia, Plasma Nitriding of the Inner Surface of Stainless Steel Tubes, Surf. Coatings Technol., 2018, 355, p 116-122

37. Z. Zhang, X. Li, and H. Dong, Response of a Molybdenum Alloy to Plasma Nitriding, Int. J. Refract. Met. Hard Mater., 2018, 72, p 388395

38. Y. Li, Y. He, J.J. Xiu, W. Wang, Y.J. Zhu, and B. Hu, Wear and Corrosion Properties of AISI, 420 Martensitic Stainless Steel Treated by Active Screen Plasma Nitriding, Surf. Coatings Technol., 2017, 329, p 184-192

39. A. Buketov, M. Brailo, S. Yakushchenko, O. Sapronov, V. Vynar, O. Bezbakh, and R. Negrutsa, Investigation of Tribological Properties of Two-Component Bidisperse Epoxy-Polyester Composite Materials for Its Use in the Friction Units of Means of Sea Transport, Period. Polytech. Mech. Eng., 2019, 63(3), p 171-182

Publisher's Note Springer Nature remains neutral with regard to jurisdictional claims in published maps and institutional affiliations. 